\section{Free Xylose in Fruits}

AN investigation of the carbohydrates present in the Victoria plum has revealed the presence of small amounts (c. 0.1 per cent fresh weight) of free xylose in the juice of ripe and immature fruits. The origin of this sugar is uncertain; it may arise from enzymic hydrolysis of a xyloside, but we consider this unlikely.

The xylose was isolated by maceration of the plum mesocarp, followed by dialysis against distilled water. The dialysate, containing the free sugars, was evaporated to a syrup in vacuo, and the xylose isolated by partition chromatography using a cellulose column ${ }^{1}$.

The xylose was characterized by paper chromatography (Whatman No. 1 paper was employed) using as solvents ethyl acetate-acetic acid-water $(9: 2: 2)$, $n$-butanol-pyridine - water (10:3:3), and phenolwater (phenol saturated with water). The chromatograms were developed by spraying with 4 per cent anisidine hydrochloride in $n$-butanol ${ }^{2}$.

Further proof of identity was obtained by the preparation of a dimethyl acetal dibenzylidene derivative.

Sufficient material was not available for accurate optical measurements, though a preliminary examination showed that it exhibited a small dextrorotation.

Evidence has also been obtained of the existence of free xylose in other varieties of mature plum, damson and quinee, and Dr. A. E. Flood and his colleagues have detected it chromatographically in young apple and pear shoots, and in the leaves of potato ${ }^{3}$.

It is hoped to continue the investigation when further supplies of fruit are available. $W \Theta$ are indebted to Dr. J. K. N. Jones for his advice and interest during this work.

Department of Biological Chemistry,

J. G. HAY

J. B. PrIDham

University, Bristol 8. March 26.

'Hough. L., Jones, J. K. N., and Wadman, W. H., J. Chem. Soc., 2511 (1949).

${ }^{2}$ Hough, I., Jones, J. K. N., and Wadman, W. H., J. Chem, Soc., $702(1950)$

${ }^{3}$ Flood, A. E. (private communication).

\section{Amino-Acids in Phloem Sap and their Excretion by Aphids}

Some results of the application of paper chromatography to the detection and estimation of amino-acids and sugars in the honey-dew excreted by aphids and coccids have been published recently by Gray ${ }^{1}$, Maltais and Auclair ${ }^{2}$, and others. What has remained obscure is the relation between the composition of the honey-dew and that of the plant sap on which these insects are feeding.

The determination of the composition of phloem sap, which is the normal food of aphids, was undertaken in 1950. The phloem sap of two-to four-yearold stems of Salix spp. was collected as it exuded through the severed mouthparts of the aphid, Tuberolachnus salignus (Gmelin), by the method outlined by Kennedy and Mittler ${ }^{3}$. Its chemical composition was compared with that of the honey-dew excreted by aphids feeding on the same stems at the same time. When equal volumes of freshly collected phloem sap and honey-dew were run side by side on chromatograms, it was found that each of the amino-acids which could be detected in the honey-dew was present in the phloem sap. All the amino-acids were in a higher concentration in the phloem sap than in the honey-dew. The chromatograms did not suggest that there was any differential absorption by the aphid of amino-acids from the sap. Acid hydrolysis of samples of sap and honey-dew did not result in any increase in the number or quantities of the amino-acids, other than aspartic and glutamic acids, at the expense of their amides. Quantitative determinations of the total nitrogen in the sap and honey-dew also showed that, over a considerable range of concentrations, the amounts of total nitrogen in the sap were always in excess of those present in the honey-dew.

These results suggest that the nitrogenous matter ingested by an aphid is in the form of free aminoacids and amides, which are usually in excess of the aphid's requirements. The free amino-acids detected in the honey-dew seem to come directly from the ingested sap, and are not to be regarded as products of protein breakdown or of the fixation of atmospheric nitrogen supposedly through the agency of the aphid's symbionts ${ }^{4}$.

It was further found that the number and the amount of amino-acids in the honey-dew depend on the extent to which these amino-acids are present in the phloem sap of the plant. The amino-acid composition of the phloem sap depends in turn on the developmental stage of the plant. As shown by Kennedy and 1300 th $^{5}$, certain leaf-feeding aphids colonize growing and senescing leaves in preference to leaves in an intermediate, fully functioning condition. The greatest variety and abundance of aminoacids in the phloem sap of the willow stems were found during the growth and senescence of their foliage. The following amino-acids and amides could then be demonstrated readily both in phloem sap and in honey-dew: aspartic acid, glutamic acid, serine, threonine, alanine, valine, leucine and/or isoleucine, phenyl alanine, asparagine, glutamine and, possibly, $\gamma$-amino-butyric acid. During the period after growth had ceased and before leaf senescence set in, however, all that could be detected were small amounts of aspartic acid, glutamic acid and their amides.

Agricultural Research Council

T. E. MrtTler

Unit of Insect Physiology,

Zoological Laboratory,

Cambridge. Feb. 24 .

${ }^{1}$ Grav, R. A., Science, 115, 129 (1952).

${ }^{2}$ Maltais, J. B., and Auclair, J. L., Canadian J. Zool., 30, 191 (1952), ${ }^{3}$ Kennedy, J. S., and Mittler, T. E., Nature, [171, 528 (1953) ].

"Toth, L., "The Biological Fixation of Atmospheric Nitrogen" (Budapest, 1946).

${ }^{5}$ Kennedy, J. S., and Booth, C. O., Ann. App. Biol., 38, 25 (1951).

\section{Feeding Mechanism of the Cichlid Fish, Tilapia esculenta Graham}

THE food of Tilapia esculenta consists mainly of phytoplankton', although zooplankton and insect larvæ ${ }^{2}$ have occasionally been recorded. Diatoms are the most important food elements of the phytoplankton, particularly the filamentous Melosira. In the evidence for his 'Law of the Distribution of the Ngege', Graham ${ }^{2}$ concluded that the simple gill-rakers of $T$. esculenta were not adapted for straining phytoplankton and that consequently the species obtained 